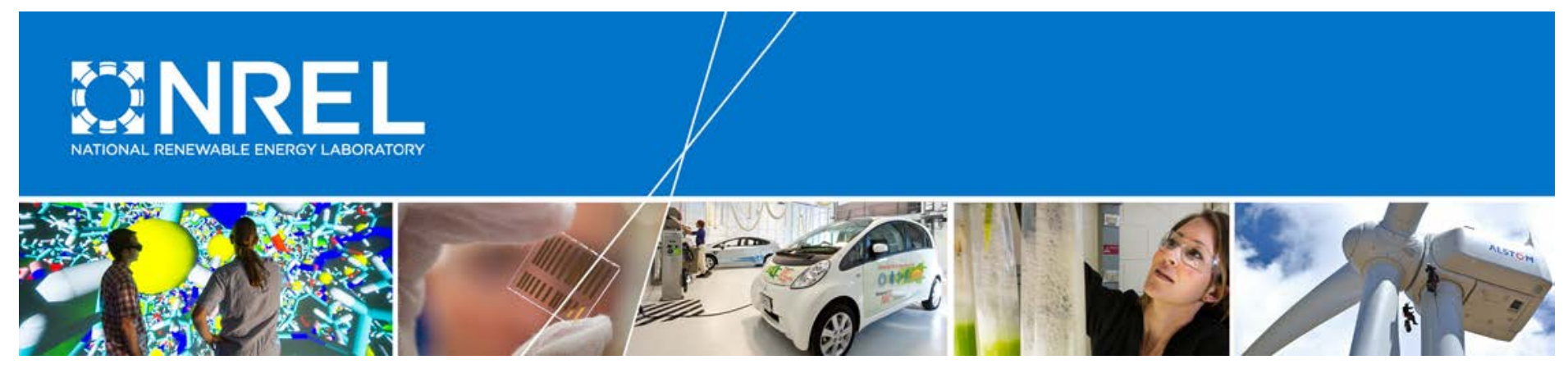

\title{
Analyzing the Impacts of Increased Wind Power on Generation Revenue Sufficiency
}

\section{Preprint}

Qin Wang, Hongyu Wu, Jin Tan, and Bri-Mathias Hodge National Renewable Energy Laboratory

Wanning Li

lowa State University

Cheng Luo

Midcontinent Independent System Operator

Presented at the 2016 IEEE Power and Energy Society

General Meeting

Boston, Massachusetts

July 17-21, 2016

(C) 2015 IEEE. Personal use of this material is permitted. Permission from IEEE must be obtained for all other uses, in any current or future media, including reprinting/republishing this material for advertising or promotional purposes, creating new collective works, for resale or redistribution to servers or lists, or reuse of any copyrighted component of this work in other works.

NREL is a national laboratory of the U.S. Department of Energy Office of Energy Efficiency \& Renewable Energy Operated by the Alliance for Sustainable Energy, LLC

This report is available at no cost from the National Renewable Energy Laboratory (NREL) at www.nrel.gov/publications.

\section{Conference Paper}

NREL/CP-5D00-65387

August 2016

Contract No. DE-AC36-08G028308 


\section{NOTICE}

The submitted manuscript has been offered by an employee of the Alliance for Sustainable Energy, LLC (Alliance), a contractor of the US Government under Contract No. DE-AC36-08GO28308. Accordingly, the US Government and Alliance retain a nonexclusive royalty-free license to publish or reproduce the published form of this contribution, or allow others to do so, for US Government purposes.

This report was prepared as an account of work sponsored by an agency of the United States government. Neither the United States government nor any agency thereof, nor any of their employees, makes any warranty, express or implied, or assumes any legal liability or responsibility for the accuracy, completeness, or usefulness of any information, apparatus, product, or process disclosed, or represents that its use would not infringe privately owned rights. Reference herein to any specific commercial product, process, or service by trade name, trademark, manufacturer, or otherwise does not necessarily constitute or imply its endorsement, recommendation, or favoring by the United States government or any agency thereof. The views and opinions of authors expressed herein do not necessarily state or reflect those of the United States government or any agency thereof.

This report is available at no cost from the National Renewable Energy Laboratory (NREL) at www.nrel.gov/publications.

Available electronically at SciTech Connect http:/www.osti.gov/scitech

Available for a processing fee to U.S. Department of Energy and its contractors, in paper, from:

U.S. Department of Energy

Office of Scientific and Technical Information

P.O. Box 62

Oak Ridge, TN 37831-0062

OSTI http://www.osti.gov

Phone: 865.576.8401

Fax: 865.576.5728

Email: reports@osti.gov

Available for sale to the public, in paper, from:

U.S. Department of Commerce

National Technical Information Service

5301 Shawnee Road

Alexandria, VA 22312

NTIS http://www.ntis.gov

Phone: 800.553 .6847 or 703.605 .6000

Fax: 703.605.6900

Email: orders@ntis.gov 


\section{Analyzing the Impacts of Increased Wind Power on Generation Revenue Sufficiency}

Qin Wang, Hongyu Wu, Jin Tan, Bri-Mathias Hodge, Wanning Li, Cheng Luo

\begin{abstract}
The Revenue Sufficiency Guarantee (RSG), as part of make-whole (or uplift) payments in electricity markets, is designed to recover the generation resources' offer-based production costs that are not otherwise covered by their market revenues. Increased penetrations of wind power will bring significant impacts to the RSG payments in the markets. However, literature related to this topic is sparse. This paper first reviews the industrial practices of implementing RSG in major US independent system operators (ISOs) and regional transmission operators (RTOs), and then develops a general RSG calculation method. Finally, an 18-bus test system is adopted to demonstrate the impacts of increased wind power on RSG payments.
\end{abstract}

Index Terms-Make-whole payment, uplifts, Revenue sufficiency guarantee (RSG), wind, impact, electricity markets

\section{INTRODUCTION}

$\mathrm{W}$ IND power is developing rapidly in the US. In 2014, wind served $5.6 \%, 9 \%$, and $10.6 \%$ of the power demand in CAISO, MISO and ERCOT, respectively [1]-[3]. The increase in wind power penetrations brings significant challenges to power system operations. Independent system operators (ISOs) and regional transmission operators (RTOs) have developed various effective approaches to accommodate wind, as well as other renewable energy resources in the markets. In MISO, a Dispatchable Intermittent Resources (DIR) mechanism was introduced in 2011 to bring wind power into the realtime market dispatch [4]. In CAISO, the approaches include setting the bid floor to negative $\$ 150 / \mathrm{MWh}$, constructing an energy imbalance market (EIM), and creating a flexible ramping product [5]. In ERCOT, the main approaches were a new market design and transmission infrastructure upgrades [6].

A number of researchers have studied the impacts of wind power on the system. The effects of wind power on thermal generation unit commitment and dispatch were studied in [7]. In addition, Morales et al. [8] analyzed the impact of wind production on the locational marginal pricing (LMP) in a poolbased electricity market. Gautam et al. [9] studied the impact of increased wind penetration on power system transient and small signal stabilities. However, to the authors' best knowledge, studies on the impacts of increased wind penetration on the system's Revenue Sufficiency Guarantee (RSG) payment are rare. The RSG payment is an important metric to measure the efficiency of the market operations [10]. This paper first reviews the industrial practice on implementing the

This work was supported by the National Renewable Energy Laboratory's MTI program under contract No. 29401506.

Qin Wang, Hongyu Wu, Jin Tan, and Bri-Mathias Hodge are with National Renewable Energy Laboratory, Golden, CO 80401 USA (e-mails: \{Qin.Wang; Hongyu.Wu; Jin.Tan; Bri.Mathias.Hodge\}@nrel.gov).

Wanning Li is with the Iowa State University, Ames, IA 50010 USA.

Cheng Luo is with the Midcontinent ISO (MISO), Carmel, IN 46032 USA.
RSG mechanism in major ISOs and RTOs in the US, and then develops a general approach for the RSG calculations. Finally, simulation results on an 18-bus test system are used to demonstrate the impacts of increased wind penetration on the RSG payments.

\section{RSG INDUSTRIAL PRACTICE}

In U.S. electricity markets generation resources are compensated for their served energy based on locational marginal prices (LMPs) [11]. In the co-optimized energy and ancillary service framework, the resources will also be compensated for the reserve services they supplied based on a market clearing price (MCP). In practice, generation resources' market payments received from the ISO can be less than their offer-based production costs and their difference, which is the so-called "RSG credit", and should be compensated by the ISO for this difference. This occurs due to many complicated reasons, such as the limitations on market modeling software, the complexity of power system operations, and the requirement to maintain system reliability Specifically, RSG payments occur during market operations for three major reasons.

First, a generator's marginal cost curve is usually nonconvex and average cost curve is not upward-sloping [13]. For example, a generator may provide the following offer parameters: 1) minimum generation level is $50 \mathrm{MW}$; 2) no load cost is $\$ 250$; and 3) the marginal cost offer has 3 segments: $\$ 30 / \mathrm{MWh}$ to operate at up to $90 \mathrm{MW}, \$ 40 / \mathrm{MWh}$ to operate between $90 \mathrm{MW}$ and $110 \mathrm{MW}$, and $\$ 48 / \mathrm{MWh}$ to operate between $110 \mathrm{MW}$ and 130MW. Then, the marginal and average costs for this generator are shown in Fig. 1. The average costs at minimum $(50 \mathrm{MW})$ and maximum $(130 \mathrm{MW})$ outputs are $\$ 35 / \mathrm{MWh}$ and $\$ 36.23 / \mathrm{MWh}$, respectively. When the generation output is $90 \mathrm{MW}$, the average cost curve reaches its lowest point which is $\$ 32.78 / \mathrm{MWh}$. The marginal cost of the unit at minimum generation level can be any value between $\$ 30 / \mathrm{MWh}$ and $\$ 35 / \mathrm{MWh}$, where $\$ 35 / \mathrm{MWh}$ is the unit's average cost at minimum generation. The average cost curve, as shown in Fig. 1, is above the marginal cost curve between $50 \mathrm{MW}$ and $90 \mathrm{MW}$. This means that if the unit is paid with the marginal cost (i.e., LMP) when its output is between 50MW and 90MW, the revenue will be lower than the cost, and the RSG credit should apply [14].

Secondly, the reliability requirement can lead to RSG payments. Market rules require that the system maintain stable operation with various source of disturbances such as: loss of a transmission/generation resource, voltage raises and dips, and reactive power inadequacy. Corrective actions are required to maintain the system's reliability and security. To enhance the system reliability, a so-called reliability-based unit commitment has been implemented besides the DA and RT markets. It can be the Forward Reliability Assessment Commitment 
(FRAC), Intra-day Reliability Assessment Commitment (IRAC), and Look-ahead commitment (LAC) in the MISO market, or the Residual Unit Commitment (RUC) and the 15minute real-time unit commitment (RTUC) in the CAISO market. The market operation process, shown in Fig. 2, is generalized from MISO, but is similar in other ISOs.

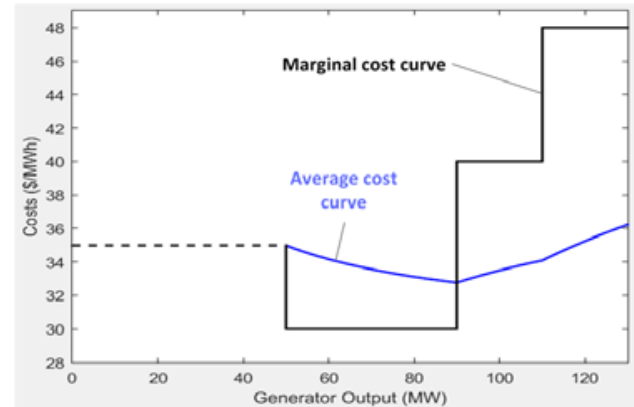

Fig. 1 Marginal and average cost curves for the example generator

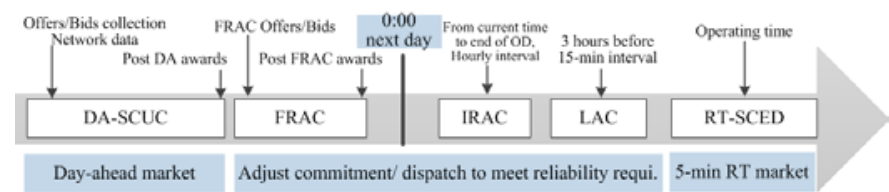

Fig. 2 Market operation process generalized from MISO [14]

Third, the DA decisions need to be adjusted due to more accurate load and wind forecasting, as well as the implementation of EMS information when close to the RT. The discrepancies between the DA and RT market operational conditions are important sources of RSG payments. For example, the mean absolute percentage error (MAPE) for MISO's DA wind forecasting was $4.87 \%$, while the RT MAPE was $3.80 \%$ in 2013 [4]. The major sources of the market variation and uncertainty that may impact the dispatch decisions are the mid-term and short-term load/wind forecast errors, NSI (net scheduled interchange) forecast errors, and dispatchable resources not following their set points.

In the rest of this section, the industrial practices for RSG mechanism are compared among the major U.S. RTOs and ISOs. It should be noted that some ISOs may call RSG by a different name, such as BCR (bid cost recovery), but the basic concepts are similar.

\section{A. Midcontinent ISO (MISO)}

In MISO, the RSG is one of the two forms of make-whole payments (MWP). RSG ensures resources cover their offerbased production costs and have incentives to participate in the market. The RSG mechanism started in 2005 when the market commenced. The un-recovered production costs of committed generation resources are allocated as follows: 1) DA RSG payments were allocated to cleared demands in the DA market, and 2) RT RSG payments were allocated to the deviations between DA and RT schedules. The resources qualified for DA RSG payments are committed primarily for two reasons: capacity purposes, which means the resource is committed in DA to meet bid-based demand and operating reserve requirements, and voltage and local reliability (VLR) purposes, which means the resource is committed to mitigate issues with transmission system voltage and other local reliability concerns. The resources qualified for RT RSG payment are primarily committed for three reasons: capacity, VLR, and constraint management, where the third refers to resources committed in the RAC or LAC processes for an Active Transmission Constraint [15]. The other form of the MWP, the price volatility MWP (PVMWP), was introduced into the market in January 2009 when MISO consolidated 27 balancing authority (BA) areas and implemented its ancillary service (AS) markets [16]. The PVMWP falls into two categories: the DA margin assurance payments and the RT offer revenue sufficiency guarantee payments.

\section{B. California ISO (CAISO)}

CAISO initiates the Bid Cost Recovery (BCR) process to ensure scheduling coordinators (SCs) are able to recover startup costs (SUC), minimum load costs (MLC), transition costs (TC), and energy bid costs [17]. Under the current BCR mechanism rule, the market revenues are netted across the individual market days and then across the DA and RT markets for the same trading day. Hence, if the resource's revenue from the DA market is enough to cover its costs for its RT schedule, it will not receive any unrecovered BCR payments. This means, any revenue from one of the DA and RT markets can offset the need to pay for shortfalls in another. Offsetting costs and revenue across the two markets can lower a resource's overall BCR, which may discourage SCs from submitting economic bids in the RT market. In 2013, CAISO proposed four modifications to its BCR accounting procedures in order to eliminate disincentives to submit RT bids [18]: 1) separation of DA and RT BCR, 2) the start-up costs of short-start resources are paid based on their DA commitment status, while the RT minimum load costs compensations are calculated from the incremental change between DA and RT, 3) modified the DA market metered energy adjustment factor, and 4) replaced the real-time metered energy adjustment factor with a real-time performance metric.

\section{New York ISO (NYISO)}

The MWP in NYISO is defined as the increased cost of generation beyond the schedules of SCUC and Balancing Market Evaluation (BME). Its major cause is the dispatching of uneconomic units to ensure the system's security. There are two types of uplift payments in NYISO. First, qualified units are compensated through NYISO's Bid Production Cost Guarantee (BPCG) mechanism when their earnings are lower than their costs. The BPCG payments will be passed on to all load serving entities (LSEs) within the state based upon their ratio share of the load. Lower uplift charges can be achieved in the New York Control Area (NYCA) when the number of unit Out of Merit (OOM) requests are reduced. For example, generation will more accurately be scheduled and dispatched initially when the $138 \mathrm{kV}$ transmission lines in NYC are modeled, thereby, decreasing the number of units calling OOM. Another type is the DA margin assurance payments (DAMAP), which is designed to protect a resource's DA margin when the RT instructions prevent the resource from meeting its DA schedule [19].

\section{ISO New England (ISO-NE)}

The ISO-NE implements a Net Commitment-Period Compensation (NCPC) mechanism to provide MWPs to market participants with resources dispatched out of economic-merit order for reliability purposes, when the resources' costs of providing energy and/or reserves would otherwise exceed the 
revenue paid to them [20]. NCPC may be paid in either the DA or RT Energy Markets. The DA NCPC evaluation is performed for generators cleared in the DA Market, while the RT NCPC payment is designed to guarantee a generator that follows the ISO's operating instructions are "no worse off" financially than the best alternative generation schedule [21]. The NCPC is composed of four components: the Voltage NCPC Payments (VAR), which is the reliability costs paid to provide voltage control, the Distribution NCPC Payments, which is the reliability costs to manage constraints on the low voltage distribution system (RT market only), the First Contingency NCPC payments, which is the reliability costs to provide first contingency coverage, and the Second Contingency NCPC payments, which is the compensation for providing adequate capacity to respond to a local second contingency [22].

\section{E. PJM Interconnection}

The PJM Interconnection clears the RT market every 5 minutes using a co-optimized energy and ancillary service algorithm. The uplift payments, or the make-whole payments, are calculated for both energy and ancillary services. In 2013, the total uplift payments in PJM was $\$ 757,699,866$ [23]. Under the uplift payment mechanism, generation and demand resources receive supplemental compensation when the full value of their offers is not recouped through the market clearing prices for energy and ancillary services. The occurrence of uplifts may be due to multiple reasons, such as the RT selfscheduling of resources even if they are not committed in DA, voltage constraints, lost opportunity cost (a resource is committed in DA but is not needed in RT), interchange volatility, unexpected outages, black start, and reactive service. It is also found that the uplift is usually correlated with high fuel prices, since resources are more expensive than normal when the natural gas prices are high [24].

\section{F. Electric Reliability Council of Texas (ERCOT)}

The MWPs paid to generators in ERCOT are to compensate their financial losses when offering specific reliability contributions to the system, mandated through reliability must run or through the reliability unit commitment (RUC) requirements [25]. ERCOT implements both RUC and an hour-ahead unit commitment to ensure adequate resources are online. One important source for collecting the MWP is the Capacity Short Charge (CSC) assessed to the qualified scheduling entities (QSEs) when they do not provide enough capacity to meet their obligations. If the revenues from the CSC do not cover all RUC MWPs, then additional funds will be uplifted to QSEs on a Load Ratio Share basis.

\section{Generalized RSG CALCUlation Method}

Rules to calculate the RSG payments in different ISOs and RTOs vary. However, the general concepts are similar, i.e., the payments are used to guarantee the cost recovery of generation resources when they are committed by the markets. Generally, there are 4 types of costs for a generation resource:

- Start-up: costs that are incurred per start-up over the run time of the resource.

- No load: Costs for operating a resource at zero MW output.
- Energy offer: the costs for a resource's willingness to sell an incremental amount of energy into the market.

- Ancillary service offer: the costs for providing ancillary service into the market.

The focus of this section is to generalize the RSG calculation formulations. To this end, the following assumptions are made. 1) Assume that the resolution time for DA and RT markets is 1 hour and 5 minutes, respectively. 2) Assume all the units follow the RT dispatch instructions perfectly. This will avoid considering the actual metered data from RT operations. 3) Only the RSG payments related to bid production cost recovery are considered. The MWPs associated with voltage control, reactive service, and security issues are not considered.

\section{A. The concept of commitment periods (CPs)}

In the DA and RT markets, a Commitment Period (CP) is a continuous unit commitment time interval bounded by ISOinstructed start-up and shut-down signals. For example, there are two CPs in Table I. If any hours in the CP are cleared as Must-Run, then the resource is not qualified for start-up cost recovery in the CP. In addition, in the hours when "MR" is cleared, the resource is not eligible for recovery of no-load, incremental energy, and ancillary service costs. For the instance in Table I, the resource is not eligible to recover startup costs in CP hour 6 to hour 9, and is not eligible to recover all other costs in hour 7 .

TABLE I. EXAMPLE OF COMMITMENT PERIODS
\begin{tabular}{|c|c|c|c|c|c|c|c|c|c|c|}
\hline Hour & 1 & 2 & 3 & 4 & 5 & 6 & 7 & 8 & 9 & 10 \\
\hline Commit & 1 & 1 & 1 & 1 & 0 & 1 & 1 & 1 & 1 & 0 \\
\hline Offer & E & E & E & E & E & E & MR & E & E & E \\
\hline
\end{tabular}

Note: "E" refers to economic offer; "MR" refers to must-run offer; $1=$ committed; and $0=$ not committed.

\section{B. Day-ahead RSG formulation}

The DA RSG for generation resource $i$ without must-run offers is formulated as follows:

$R S G_{i}^{D A}=$

$\max \left\{\sum_{n=1}^{N C P} \sum_{h=1}^{H_{n}} \int_{P_{i}^{n, h, D A, \text { min }}}^{P_{i}^{n, h, D A}} \mathrm{C}_{i}^{n, h, D A}+N L C_{i}^{n, h, D A} \times P_{i}^{n, h, D A, \min }+\right.$
$\left.S U C_{i}^{n, h, D A} \times I_{i}^{n, h, D A}-L M P_{i}^{n, h, D A} \times P_{i}^{n, h, D A}+A S R_{i}^{n, h, D A}, 0\right\}$

where

$N C P$ : Number of CPs in the 24 hour intervals of nextday.

$H_{n}$ : The total hours number of the $n$th CP.

$P_{i}^{n, h, D A, \min }$ : The DA minimum generation level of resource $i$ at the $h$ th hour of $n$th CP.

$P_{i}^{n, h, D A}: \quad$ The DA cleared energy of resource $i$ at the $h$ th hour of $n$th CP.

$C_{i}^{n, h, D A}$ : The incremental DA energy offer submitted by resource $i$ at the $h$ th hour of $n$th CP.

$N L C_{i}^{n, h, D A}$ : DA no-load cost offer of resource $i$.

$S U C_{i}^{n, h, D A}$ : DA start-up cost of resource $i$.

$I_{i}^{n, h, D A}$ : Equals to 1 if resource $i$ started up at the $h$ th hour of $n$th CP; 0 otherwise.

$L M P_{i}^{n, h, D A}$ : The DA energy price of resource $i$. 
$A S R_{i}^{n, h, D A}: \quad$ The net ancillary service revenue of resource $i$ at the $h$ th hour of $n$th CP.

The net ancillary service revenue is shown in (2):

$$
\begin{gathered}
A S R_{i}^{n, h, D A}=\left(R C_{i}^{n, h, D A}-\operatorname{Reg} M C P_{i}^{n, h, D A}\right) \times R_{i}^{n, h, D A}+ \\
\left(S R C_{i}^{n, h, D A}-S R M C P_{i}^{n, h, D A}\right) \times S R_{i}^{n, h, D A}
\end{gathered}
$$

where

$$
R C_{i}^{n, h, D A}: \quad \text { DA regulation offer for resource } i \text {. }
$$

$\operatorname{RegMCP} P_{i}^{n, h, D A}: \quad$ Cleared DA regulation MCP of resource $i$.

$R_{i}^{n, h, D A}$ : Cleared DA regulation MW of resource $i$.

$S R C_{i}^{n, h, D A}$ : DA spinning reserve offer for resource $i$.

$S R M C P_{i}^{n, h, D A}$ : Cleared DA spinning reserve MCP of resource $i$.

$S R_{i}^{n, h, D A}$ : Cleared DA spinning reserve $\mathrm{MW}$ of resource $i$.

When there are must-run offers for generation resource $i$ in DA, the RSG will be adjusted following the rules in section A.

\section{Real-time RSG formulation}

The RT RSG payment covers the net revenue deviations between DA and RT markets. At the beginning of this section it is assumed that the resolution time for the RT market is $5 \mathrm{mi}$ nute, thus there will be 12 dispatch intervals for each hour in RT. The RT RSG is calculated hourly by integrating the 5-min solutions into hourly time-weighted volumes.

The hourly integrated RT energy revenue deviation for generation resource $i$ at hour $h$ is:

$R E V E N U E_{i}^{h, R T}=\Delta P_{i}^{h} \times L M P_{i}^{h, R T}$

where $\Delta P_{i}^{h}$ is the deviation of cleared energy between DA and $\mathrm{RT}$ at hour $h$ where the RT volume is integrated by hour. $L M P_{i}^{h, R T}$ is RT hourly integrated energy price.

The hourly integrated RT production cost deviation for generation resource $i$ at hour $h$ is:

$P C_{i}^{h, R T}=\frac{1}{12} \sum_{t=1}^{12} \int_{P_{i}^{h, D A}}^{P_{i, t}^{R T}} \operatorname{Inc} E_{i, t}^{h}\left(p_{i, t}^{h}\right) d p_{i, t}^{h}$

where $t$ is the interval in hour $h, P_{i}^{h, D A}$ is the DA cleared energy at hour $h$ for resource $i, P_{i, t}^{R T}$ is the RT cleared energy at $t$ th interval for resource $i, \operatorname{Inc} E_{i, t}^{h}\left(p_{i, t}^{h}\right)$ is the RT incremental offer curve function with energy $p_{i, t}^{h}$ at the th interval of hour $h$.

By using the hourly integrated revenue and cost function in (3) and (4), the RT RSG can be expressed similarly to (1). To avoid redundancy, the detailed formulation for RT RSG is not listed. Instead, a numerical example is demonstrated to calculate the RT RSG.

Assume a unit's DA and RT offer for a specific hour is as follows: start-up cost is 0 , no-load cost is $\$ 300 / \mathrm{hr}$, incremental energy offer is $\$ 7 / \mathrm{MWh}$, and spinning reserve offer is $\$ 0.5 / \mathrm{MWh}$. The DA market clearing result for this hour is as follows: the DA cleared energy and spinning reserve are 120 MWh and 8MWh, respectively; the DA LMP and DA spinning reserve MCP (Spin MCP) are $\$ 8 / \mathrm{MWh}$ and $\$ 1 / \mathrm{MWh}$, respectively. Then, the DA revenues from energy and spinning reserve are $\$ 960$ and $\$ 8$, respectively. The DA costs of energy and spinning reserve are $\$ 1140$ and $\$ 4$. The profit of this unit in DA market at this hour is negative $\$ 176$.

\begin{tabular}{|r|r|r|r|r|}
\hline $\begin{array}{r}\text { TABLE II. RT MARKET CLEARING RESULT EXAMPLE } \\
\text { Intervals }\end{array}$ & $\begin{array}{r}\text { Cleared Ener- } \\
\text { gy (MWh) }\end{array}$ & $\begin{array}{r}\text { RT LMP } \\
(\text { \$/MWh })\end{array}$ & $\begin{array}{r}\text { Cleared Spin } \\
\text { resv. (MWh })\end{array}$ & $\begin{array}{r}\text { RT SpinMCP } \\
(\$ / M W h)\end{array}$ \\
\hline 1 & 120 & 8 & 8 & 1 \\
\hline 2 & 120 & 8 & 8 & 1 \\
\hline 3 & 120 & 8 & 8 & 1 \\
\hline 4 & 120 & 8 & 8 & 1 \\
\hline 5 & 120 & 8 & 8 & 1 \\
\hline 6 & 120 & 8 & 8 & 1 \\
\hline 7 & 120 & 8 & 8 & 1 \\
\hline 8 & 120 & 8 & 0 & 0.25 \\
\hline 9 & 140 & 5 & 0 & 0.25 \\
\hline 10 & 140 & 5 & 0 & 0.25 \\
\hline 11 & 140 & 5 & 0 & 0.25 \\
\hline 12 & 140 & 5 & & 8 \\
\hline
\end{tabular}

The RT market clearing result for the 12 intervals is shown in Table II. The hourly average cleared RT energy is 126.67 MW. The hourly weighted RT LMP is $\$ 6.89 / \mathrm{MWh}$. The hourly integrated spinning reserve clearing quantity and spinning reserve $\mathrm{MCP}$ are $5.33 \mathrm{MWh}$ and $\$ 1 / \mathrm{MWh}$, respectively. The cleared energy deviation between DA and RT is (126.67-120) $=6.67 \mathrm{MWh}$. Thus, the RT energy profit deviation is $6.67 \mathrm{MWh} \times \$(6.89-7) / \mathrm{MWh}=-\$ 0.73$, which is negative. The cleared spinning reserve deviation between DA and RT equals to $(5.33-8)=-2.67 \mathrm{MWh}$. Thus, the RT spinning reserve profit deviation is $-2.67 \mathrm{MWh} \times \$(1-0.5) / \mathrm{MWh}=-\$ 1.335$, which is also negative. The overall RT RSG for this hour would be $\$ 2.065$.

\section{CASE Study}

An 18-bus test system extracted from the case library of the PSLF simulation tool [26] is used to demonstrate the impact of improved wind penetration on RSG. The one-line diagram of the system is shown in Fig. 3, which includes 18 buses, 24 branches, 5 generators, and 7 loads. The resource type and economic data of the generators are shown in Table III. The one-segment incremental energy offer prices for G1, G2, G3, and $\mathrm{G} 4$ are $\$ 18.14, \$ 1, \$ 1$, and $\$ 19.79$, respectively, with bid energy being from $0 \mathrm{MW}$ to their maximum capacities. The output of wind generator G5 is fixed as the time-series actual wind power data. The maximum load is $2,979.45 \mathrm{MW}$ in hour 19 of the day. The regulation and spinning reserves are set to $1 \%$ and $3 \%$ of the load, respectively.

The FESTIV (flexible energy scheduling tool for integrating variable generation) [27] tool developed by the National Renewable Energy Laboratory (NREL) is used to simulate the system operation. FESTIV can simulate the behavior of the electric power system under high penetrations of variable and uncertain renewable energy resources in day-ahead (DA), hour-ahead (HA), and real-time (RT) markets. Four different wind penetration scenarios were simulated with FESTIV:

- Basecase: with the above system data. The simulation results show $76.5 \%$ energy is from hydro, $17.9 \%$ is from thermal, and $5.6 \%$ is from wind.

- Scenario 1, Scenario 2 and Scenario 3: Increase the wind energy to $150 \%, 200 \%$, and $300 \%$ of the basecase, respectively, and keep the input of other generation resources unchanged. 


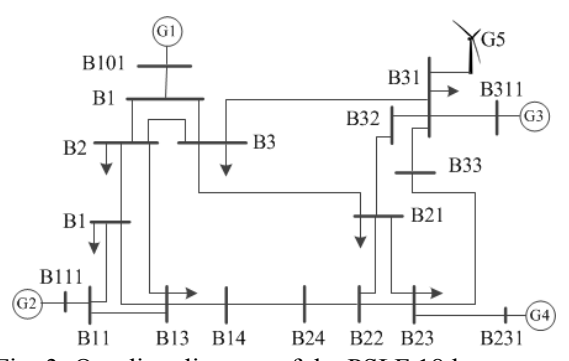

Fig. 3. One-line diagram of the PSLF 18 bus system

TABLE III. GENERATOR ECONOMIC OFFERS

\begin{tabular}{|l|l|l|l|l|l|}
\hline & $\begin{array}{l}\text { Min Cap. } \\
(\mathrm{MW})\end{array}$ & $\begin{array}{l}\text { Max Cap. } \\
(\mathrm{MW})\end{array}$ & $\begin{array}{l}\text { No-load } \\
\text { cost (\$) }\end{array}$ & $\begin{array}{l}\text { Start-up } \\
\text { cost (\$) }\end{array}$ & Type \\
\hline G1 & 250 & 550 & 18.14 & 3955 & Thermal \\
\hline G2 & 1 & 1200 & 0 & 0 & Hydro \\
\hline G3 & 1 & 1200 & 0 & 0 & Hydro \\
\hline G4 & 200 & 600 & 19.79 & 4746 & Thermal \\
\hline G5 & 0 & 370 & 0 & 0 & Wind \\
\hline
\end{tabular}

Table IV. DA and RT RSGs for different scenarios

\begin{tabular}{|r|r|r|r|r|}
\hline & Basecase & Scenario 1 & Scenario 2 & Scenario 3 \\
\hline DA revenue (\$) & 111,933 & 86,180 & 60,552 & 60,552 \\
\hline DA cost (\$) & 252,104 & 249,608 & 247,757 & 244,368 \\
\hline DA RSG (\$) & 140,171 & 163,428 & 187,205 & 183,816 \\
\hline RT revenue $^{*}(\$)$ & 3,848 & 3,887 & 3,427 & 1,334 \\
\hline RT cost $^{*}(\$)$ & 702 & 3,198 & 2,394 & 1,626 \\
\hline RT RSG (\$) & 0 & 0 & 0 & 292 \\
\hline Overall RSG (\$) & $\mathbf{1 4 0 , 1 7 1}$ & $\mathbf{1 6 3 , 4 2 8}$ & $\mathbf{1 8 7 , 2 0 5}$ & $\mathbf{1 8 4 , 1 0 8}$ \\
\hline
\end{tabular}

${ }^{*}$ RT revenue and cost are calculated based on the deviations of schedules between DA and RT

After the FESTIV runs finish, use the methodology developed in Section III to calculate the RSGs for the four scenarios. The results are shown in Table IV. The DA RSG was calculated based on the generation resources' DA revenue and bid-based cost. When the wind penetration increases to $200 \%$ of the basecase level, both the DA revenue and the DA costs decrease. However, the rate of decrease of the former is larger than the latter. This is because when the wind penetration increases, the marginal unit in the system changes from the (relatively expensive) thermal unit to the (relatively cheaper) hydro unit; thus the LMP of the system changes significantly. Comparing the $200 \%$-wind and $300 \%$-wind scenarios, the DA revenue remains unchanged but the DA cost decreases. The reason why the revenue is the same is because in the two scenarios the marginal units are both hydro and thus the LMPs are the same (which equals the marginal cost of hydro, i.e., $\$ 1 / \mathrm{MWh}$ ). The reason why the costs decrease in the two scenarios is because the cheap wind replaces more thermal and hydro generation in the $300 \%$ wind scenario. The RT RSG was calculated based on the hourly-integrated price and dispatch deviations between DA and RT. A positive revenue deviation value means that a unit's RT dispatch volume is higher than the DA schedule and thus it can sell the excess energy at the RT price in the RT market. It is shown in Table IV that the RT RSGs are zero for the basecase, Scenario 1, and Scenario 2 because the cost deviations are lower than the revenue deviations. The RT RSG in Scenario 3 is non-zero because the RT cost deviation is higher than the RT revenue deviation. In this isolated system, the overall RSG increases with higher wind penetration levels, but then decreases slightly when the penetration level passes a certain value.

\section{CONCLUSION}

This paper reviews the industrial practices on implementing RSG mechanisms in major US RTOs and ISOs. The generalized RSG calculation methods are developed for both dayahead and real-time electricity markets based on current industrial practices. The DA RSG ensures that generation resources committed in the DA market can recover their three-part offers, while the RT RSG can guarantee the cost recovery for the deviation quantity between RT and DA markets. Simulation results from an 18-bus system demonstrate that the overall RSG payment increases initially when wind penetration levels increase, but decreases slightly after the penetration level passes a certain value.

\section{REFERENCES}

[1] CAISO, 2014 annual report on market issues\& performance, June 2015.

[2] MISO, Market Reports library, <https://www.misoenergy.org/Library/M arketReports/Pages/MarketReports.aspx $>$.

[3] ERCOT, 2014 total energy use in ERCOT region up by 2.5 percent from 2013, <http://www.ercot.com/news/press_releases/show/51654>, 2015.

[4] K. Ruud, Wind forecast integration at MISO, 2014 IEEE PES presentation.

[5] D. Howarth and B. Monsen, "Renewable energy faces daytime curtailment in California," Project Finance Newswire, Nov. 2014.

[6] L. Bird, J. Cochran, and X. Wang, "Wind and solar energy curtailment: experience and practices in the United States," NREL technical report, Mar. 2014.

[7] B. C. Ummels, et al., "Impacts of wind power on thermal generation unit commitment and dispatch," IEEE Trans. Energy Conv., vol. 22, pp. 44-51, 2007.

[8] J. M. Morales, A. J. Conejo, and J. Perez-Ruiz, "Simulating the impact of wind production on locational marginal prices," IEEE Trans. Power Syst., vol. 26, pp. 820-828, 2011.

[9] D. Gautam, V. Vittal, and T. Harbour, "Impact of increased penetration of DFIG-based wind turbine generators on transient and small signal stability of power systems," IEEE Trans. Power Syst., vol. 24, no. 3, pp. 1426-1434, 2009

[10] W. W. Hogan, "Revenue sufficiency guarantees and cost allocation," May 2006.

[11] Q. Wang, G. Zhang, J. D. McCalley, T. Zheng, and E. Litvinov, "Riskbased locational marginal pricing and congestion management," IEEE Trans. Power Syst., vol. 29, pp. 2518-2528, 2014.

[12] FERC, "Uplift in RTO and ISO markets," August 2014.

[13] MISO, "Convex Hull Pricing Stakeholder Workshop,” May 3, 2010.

[14] MISO, "BPM 002 - Energy and Operating Reserve Markets."

[15] MISO, "BPM 005 - Market Settlements."

[16] MISO, "MISO make-whole payment overview," PJM Energy Market Uplift Senior Task Force, December 2014.

[17] CAISO, "Settlements and billing configuration guide: real-time bid cost recovery allocation, version 5.4," 2015.

[18] CAISO, "Tariff Amendment: Bid cost recovery mitigation measures," Sep. 25, 2013

[19] NYISO, "Accounting and billing manual," Dec. 2014.

[20] NYISO, "Net commitment-period compensation," <http://www.iso-ne.c om/markets-operations/markets/ncpc $>$.

[21] NYISO, "Real-Time (RT) Net Commitment Period Compensation (NCP C)," Available at $<$ http://www.iso-ne.com/markets-operations/settlemen ts/understand-bill/item-descriptions/rt-ncpc $>$.

[22] ISO-NE, "Transmission, Markets, and Services Tariff: Market Rule 1."

[23] A. Keech, "Uplift in PJM," Available at <http://www.caiso.com/Docum ents/4 PJM_MarketOverview.pdf>.

[24] F. S. Bresler, "Energy and Ancillary Services Uplift in PJM," FERC Uplift Workshop, Sep. 8, 2014.

[25] Potomac Economics, "2012 State of the market report for the ERCOT wholesale electricity markets," Jun. 2013

[26] GE Energy, "Positive Sequence Load Flow software (PSLF)," <http://w ww.geenergyconsulting.com/practice-area/software-products/pslf $>$.

[27] E. Ela, and M. O'Malley, "Studying the variability and uncertainty impa cts of variable generation at multiple timescales," IEEE Trans. Power S yst., vol. 27, pp. 1324-1333, 2012. 